\title{
A Retrospective Cross-Sectional Study of the Utility of Cartridge-Based Nucleic Acid Amplification Test in Diagnosis of Pulmonary and Extrapulmonary Tuberculosis in People Living with HIV in Second Highest HIV Prevalent State in India
}

\author{
Tade Bagbi ${ }^{1} \quad$ Ningthoukhongjam Reema ${ }^{2} \quad$ S. Bhagyabati Devi ${ }^{2} \quad$ Thangjam Gautam Singh ${ }^{3}$ \\ Mohammad Jaleel $^{2} \quad$ Ravi Nishad ${ }^{2}$
}

${ }^{1}$ Department of Internal Medicine, District Hospital, Daporijo, Arunachal Pradesh, India

2Department of Medicine, Regional Institute of Medical Sciences (RIMS), Imphal, Manipur, India

${ }^{3}$ Department of Radiodiagnosis, Shija Hospitals and Research Institute, Langol, Imphal, Manipur, India

\begin{abstract}
Address for correspondence Ningthoukhongjam Reema, MBBS, MD, PGDGM, CCEBDM, c/o Dr Thangjam Gautam Singh, RIMS Road, Opposite Babina Clinic, Imphal West, Manipur 795004, India (e-mail: thangjamreema@gmail.com).
\end{abstract}

\begin{abstract}
Keywords

- CBNAAT

- pulmonary

tuberculosis

- rifampicin resistance

- sputum AFB

- extrapulmonary

tuberculosis

- HIV

Introduction Tuberculosis (TB) in people living with human immunodeficiency virus (PLHIV) is difficult to diagnose due to fewer organisms in sputum and extrapulmonary samples. Sputum culture takes 4 to 8 weeks for growth of the mycobacteria. Delayed treatment for TB in PLHIV leads to increased mortality. This study evaluated cartridge-based nucleic acid amplification test (CBNAAT) as a diagnostic tool for diagnosis of pulmonary TB (PTB) and extrapulmonary TB (EPTB) in PLHIV in the second most HIV prevalent state in India and for comparing its efficacy between Ziehl-Neelsen (ZN) staining sputum smear-positive and sputum smear-negative TB.

Methods This cross-sectional study was conducted in RIMS, Imphal, with 167 PLHIV patients, age 15 years or older, having signs and symptoms of TB. Appropriate samples for sputum microscopy and CBNAAT were sent.

Conclusion The overall sensitivity of sputum smear for acid-fast bacillus (AFB) was found to be $30.71 \%$ and that of CBNAAT was $38.57 \%$. Sensitivity of CBNAAT for sputum smear-positive and sputum smear-negative TB was 100 and $11.3 \%$, respectively. Sensitivity of ZN smear for AFB of EPTB sample was $48.1 \%$ and that of CBNAAT was $59.25 \%$. In both PTB and EPTB, CBNAAT showed an increase in diagnosis of microbiologically confirmed PTB cases by 7.8 and $11.1 \%$, respectively, over and above the cases diagnosed by ZN smear microscopy. Rifampicin resistance was detected in five patients. We conclude that CBNAAT is a rapid test with better sensitivity in diagnosis of PTB and EPTB in PLHIV, compared with ZN smear microscopy. It detects rifampicin resistance for multidrug-resistant TB and helps in early treatment intervention.
\end{abstract}

DOI https://doi.org/ $10.1055 / \mathrm{s}-0041-1730242$ ISSN 2455-7420
C2021. Medical and Surgical Update Society.

This is an open access article published by Thieme under the terms of the Creative Commons Attribution-NonDerivative-NonCommercial-License, permitting copying and reproduction so long as the original work is given appropriate credit. Contents may not be used for commercial purposes, or adapted, remixed, transformed or built upon. (https://creativecommons.org/licenses/by-nc-nd/4.0/). Thieme Medical and Scientific Publishers Pvt. Ltd. A-12, 2nd Floor, Sector 2, Noida-201301 UP, India 


\section{Introduction}

Human immunodeficiency virus (HIV) and tuberculosis (TB) are still considered important causes of mortality and morbidity in developing countries. More than 9 million new active cases of TB and 6 million new cases of HIV infection are reported worldwide. ${ }^{1}$ A total of 14 million cases of HIV-TB coinfection worldwide are recorded. ${ }^{2}$ India has one of the world's highest burdens of both HIV infection (2.3 million prevalent cases) and TB (\$2.1 million cases annually). ${ }^{1}$ As per the National AIDS Control Organization, Manipur has the second highest prevalence rate of HIV (1.43\%) among the Indian states. The two pathogens, Mycobacterium tuberculosis and HIV, synergistically affect the host, causing impairment of immunity. ${ }^{3} \mathrm{HIV}$ coinfection is known to aggravate severity of latent $\mathrm{TB}$ and worsens TB infection by 20 times. ${ }^{4} \mathrm{~TB}$, on the other hand, is the most common cause of death in AIDS patients (1.8 million death). ${ }^{3}$

The menace of TB is still a concern due to inaccurate diagnostic tools such as direct smear microscopy, culture, tuberculin skin testing, and chest X-ray. ${ }^{5-7}$ This may be secondary to low counts of M. tuberculosis bacilli (MTB) at the site of diseased tissue and difficulty in obtaining clinical samples of deep organs for diagnosis of extrapulmonary TB (EPTB). Globally, EPTB constitutes about $20 \%$ of all diagnosed cases of TB. ${ }^{8}$ Moreover, HIV-infected persons with TB are more likely to have negative typical X-ray finding of PTB (cavity, upper lobe infiltrates, and focal infiltrates) and negative sputum smears, ${ }^{9}$ thereby causing delay and missed diagnosis of TB in HIV-infected patients.

Unfortunately, in rural areas there is no rapid test, and culture diagnostics and molecular line probe assays are costly, with inadequate biosafety measures and insufficient trained staff making detection of early TB difficult. ${ }^{10,11}$ The Löwenstein-Jensen method, being a culture-based "gold standard test," takes several weeks to produce result, with simultaneous progression of the disease in the meantime. Thus, many active TB patients remain undiagnosed and continue to spread the disease in the community. Cartridge-based nucleic acid amplification test (CBNAAT) assay ${ }^{12}$ is a simplified type of automated molecular polymerase chain reaction (PCR) that can detect TB and does screening for multidrug resistance. It takes 2 to 3 hours to detect MTB and rifampicin resistance from one sputum sample. ${ }^{13}$ WHO recommends the use of CBNAAT assay as initial diagnostic test for suspected multidrug-resistant TB (MDR-TB) or TB-HIV coinfection. ${ }^{14,15}$ There has been a scarcity of data regarding diagnostic role of CBNAAT, specially in diagnosis of sputum smear-negative PTB cases, from the population of Manipur, a northeastern state of India (having the second highest HIV rate). In this background, the present study was undertaken to evaluate the diagnostic role of CBNAAT assay in PTB and EPTB in people living with HIV (PLHIV) and to compare the sensitivity of CBNAAT with Ziehl-Neelsen (ZN) staining microscopy in diagnosing PTB in HIV-infected patients.

\section{Materials and Methods}

We have conducted this cross-sectional study in the Department of Medicine and Centre of Excellence (COE), ART Centre, RIMS, within a period of 2 years from September 2016 to August 2018. HIV-positive patients suspected of TB infection were included in our study based on the following criteria.

\section{Inclusion Criteria}

- Age above 15 years.

- Features suggestive of RTB and EPTB according to Revised National TB Control Programme (RNTCP) guidelines:

- Persistent fever and/or cough for 2 weeks or more.

- Loss of weight (loss of $>10 \%$ of highest weight recorded in the past 3 months).

- Loss of appetite.

- History of contact with infectious TB cases.

\section{Exclusion Criteria}

- Those receiving treatment for TB.

- Unwilling patients.

\section{Sample Size}

The sample size was estimated using the formula:

$$
\begin{aligned}
\mathrm{TP}+\mathrm{FN} & =z^{2}[\mathrm{SN}(1-\mathrm{SN})] w^{2}, \\
N S N & =(\mathrm{TP}+\mathrm{FN}) p,
\end{aligned}
$$

where TP is the true positive and FN is the false negative.

The values of sensitivity (SN) ${ }^{16}$ of CBNAAT and prevalence $(p)^{17}$ of HIV-TB coinfection were taken to be 82.3 and $55 \%$, respectively, from a previous study with accuracy $(w)$ of $2 \%$ and allowable error $(z)$ of $5 \%$ :

$$
\mathrm{TP}+\mathrm{FN}=5^{2} \times\left[82.3(100-82.3] 2^{2}=9104.43\right.
$$

Now, sample size $=(\mathrm{TP}+\mathrm{FN}) / p=910455=165.5$.

Thus, the calculated sample size is equal to 166 .

\section{Study Variable}

The study included demographic data such as age, sex, symptoms, CBNAAT, ZN staining for AFB, and blood tests (hemoglobin, serum albumin, random blood sugar, fasting lipid profile, serum creatinine, total leucocyte count, CD4 count, and viral load).

\section{Working Definitions}

- HIV infection: HIV infection is diagnosed as per the NACO guideline. HIV infection is screened by Comb Aids-RS (kit 1) by the principle of ELISA (enzyme-linked immunosorbent assay) and confirmed by AIDSCAN Trispot Test Kit (kit 3) and Meriline (kit 2) by the principle of immunofiltration and immunoconcentration, respectively.

- Clinically diagnosed TB case ${ }^{18}$ :

- A bacteriologically confirmed ТВ case is one from whom a biological specimen is positive by smear microscopy, culture, or CBNAAT.

- clinically diagnosed TB case is defined as one who fulfills clinical symptoms with diagnosis on X-ray/histology and is given full course of TB medications. This group does not have bacteriological confirmation

- Presumptive PTB defines a person with any of the symptoms and signs suggestive of PTB such as more than 2 weeks of fever, cough, or significant weight loss, hemoptysis, or abnormal chest X-ray. 
- Presumptive EPTB is suspected in patients having any constitutional symptoms, such as fever for more than 2 weeks, night sweats, and weight loss, or any symptoms specific to organs, such as node swelling.

\section{CBNAAT/GeneXpert}

It is a nucleic acid amplification test (NAAT) which uses PCR. It is used in identification and amplification of genomic DNA sequences of MTB and rifampicin resistance. It also detects the mutation (leading to rifampicin resistance) in RNA polymerase $\beta$ (rpoB). GeneXpert model GX IV (GXIV-4-D) is manufactured by Cepheid Inc (United States). It has $89 \%$ sensitivity and $99 \%$ specificity when used as an initial test to replace smear microscopy. And it has a sensitivity of $67 \%$ and a specificity of $99 \%$ when used as an adjunct for smear-negative microscopy. Sensitivity and specificity were slightly higher when 3 samples were tested. ${ }^{8}$

\section{Procedure}

A cartridge-containing mixture (sputum + reagent, provided with the assay) is placed in the GeneXpert machine. All further processing is fully automated. Samples (except urine and blood) were sent to Intermediate Reference Laboratory, Imphal. sA composite diagnostic index (comprising radiology and/or clinical judgment) was considered as the reference standard for diagnosis of TB in this study and compared with the result of CBNAAT.

\section{Viral Load}

Viral load was quantified with real-time PCR technique (COBAS TagMan 48 Analyser (Roche Molecular Systems Inc., United States).

\section{Statistical Analysis}

Statistical analysis was performed using IBM SPSS Statistics version 21. For validity test of CBNAAT of sputum in diagnosis TB, the SA composite diagnostic index was considered as the reference standard and result of CBNAAT was compared with that composite diagnostic index. All $p$-values < 0.05 were considered significant.

\section{Approval of Research Ethics Board}

Ethical approval was obtained from the Research Ethics Board, Regional Institute of Medical Sciences, Imphal (Refno.A/206/REBComm(SP)/RIMS/2015/149/17/2016).

Informed written consent was obtained from the respondents.

\section{Results}

A total of 167 patients were enrolled for the study. Out of these, 140 were PTB cases and 27 were EPTB cases. Majority of them had moderate anemia with hemoglobin level of 8 to $10.9 \mathrm{mg} / \mathrm{dL}$ (males, 51\%; females, $61.2 \%$ ). More than half of the patients (58.2\%) had serum albumin of less than $2.8 \mathrm{~g} / \mathrm{dL}$. Majority of the patients had random blood sugar level of 79 to $140 \mathrm{mg} / \mathrm{dL}$ (60.4\%) and hypertriglyceridemia. Also, 73.7\% had serum cholesterol level of less than $200 \mathrm{mg} / \mathrm{dL}$, and $71.1 \%$ had serum triglycerides level of less than $150 \mathrm{mg} / \mathrm{dL}$. In addition, $58.6 \%$ of the total patients had total leucocyte count of less than 4,000/L. At the time of presentation, $61.1 \%$ had CD4 count of less than 100 cells $/ \mathrm{mm}^{3}$ and $93.4 \%$ had viral load of more than 1,000 copies/mL.

Among the presenting symptoms of the patients, the commonest was fever (98.8\%), followed by loss of appetite $(93.4 \%)$ ( - Table 1). Sputum smear for AFB was positive in $30.71 \%$ (43 out of 140 cases) and sputum for CBNAAT detected TB in 54 patients. CBNAAT was found to be positive in all $43(100 \%)$ cases of sputum smear-positive PTB, but in 11 out of 97 (11.3\%) cases of sputum smear-negative PTB ( $p$ $<0.001$ ). Thus, sputum for CBNAAT testing resulted in a relative increase in detection rate of microbiologically confirmed TB cases by $7.8 \%$ compared with sputum smear microscopy (-Table 2).

Overall, in this study population, sensitivity of sputum smear for AFB was only $30.71 \%$, with specificity of $100 \%$, while the overall sensitivity of sputum CBNAAT was $38.57 \%$, with specificity of $100 \%$ ( - Table 3 ). Sensitivity of CBNAAT

Table 1 Presenting symptoms of the patients

\begin{tabular}{|l|l|l|}
\hline Symptoms & $\begin{array}{l}\text { Frequency } \\
(\boldsymbol{n}=\mathbf{1 6 7})\end{array}$ & $\begin{array}{l}\text { Percentage } \\
(\%)\end{array}$ \\
\hline Fever ( $\geq 2 \mathrm{wk})$ & 165 & 98.8 \\
\hline Loss of appetite & 156 & 93.4 \\
\hline Cough ( $\geq 2 \mathrm{wk})$ & 136 & 81.4 \\
\hline $\begin{array}{l}\text { Weight loss }(>10 \% \text { of high- } \\
\text { est weight recorded in the } \\
\text { past 3 mo) }\end{array}$ & 117 & 70 \\
\hline Lymphadenopathy & 14 & 8.3 \\
\hline Headache & 9 & 5.3 \\
\hline Shortness of breath & 6 & 3.5 \\
\hline Hemoptysis & 3 & 1.7 \\
\hline Abdomen pain & 2 & 1.1 \\
\hline Abdomen distension & 1 & 0.5 \\
\hline
\end{tabular}

Table 2 Diagnostic yield of CBNAAT versus sputum smear microscopy

\begin{tabular}{|l|l|l|l|l|}
\hline & Sputum AFB smear-positive & Sputum AFB smear-negative & Total & $p$-Value \\
\hline CBNAAT sputum-positive & $43(30.7 \%)$ & $11(7.8 \%)$ & 54 & $<0.001$ \\
\hline CBNAAT sputum-negative & 0 & $86(61.4 \%)$ & 86 & 140 \\
\hline Total & 43 & 97 & 140 \\
\hline
\end{tabular}

Abbreviations: AFB, acid-fast bacillus; CBNAAT, cartridge-based nucleic acid amplification test. 
Table 3 Diagnostic sensitivity and specificity of CBNAAT in PTB

\begin{tabular}{|l|l|l|l|l|l|}
\hline & Sensitivity & Specificity & $\begin{array}{l}\text { Positive } \\
\text { predictive value }\end{array}$ & $\begin{array}{l}\text { Negative } \\
\text { predictive value }\end{array}$ & $\begin{array}{l}\text { Negative } \\
\text { likelihood ratio }\end{array}$ \\
\hline Overall PTB & $38.57 \%$ & $100 \%$ & $100 \%$ & $20.35 \%$ & 0.37 \\
\hline
\end{tabular}

Abbreviation: PTB, pulmonary tuberculosis.

was found to be $100 \%$ for microbiologically confirmed PTB, but sensitivity came down to $11.3 \%$ for sputum smear-negative PTB ( - Table 4 ).

The overall sensitivity of ZN smear for AFB of EPTB sample was only $48.1 \%$, while that of CBNAAT was $59.25 \%$ (- Table 5). Of the 27 EPTB cases, maximum $(14 ; 8.3 \%)$ were cases of lymph node TB (LNTB), followed by TB pleural effusion ( $5 ; 2.9 \%)$, cerebrospinal fluid (CSF) $(5 ; 2.9 \%)$, Koch's abdomen 2 (1.1\%), and pericardial TB 1 (0.5\%). Sensitivity of CBNAAT for lymph node specimens was observed to be $78.57 \%$, that for pleural fluid and CSF was 20\%, and that for ascetic and pericardial fluid was $100 \%$. CBNAAT was found to be positive in all 13 cases (100\%) of ZN smear-positive EPTB. CBNAAT was also found to be positive in 3 cases ( 2 ascitic and 1 pericardial fluid) out of 14 (21.4\%) cases of ZN smear-negative ЕРТВ (-Table 6). Only five patients (3.5\%) of PTB were detected to have rifampicin resistance ( - Table 7 ).

\section{Discussion}

India accounts for around one-fourth of the global $\mathrm{TB}$ cases. ${ }^{19}$ In sputum smear, detection of AFB is simple, rapid, inexpensive, and specific for diagnosis for PTB; however, it has low sensitivity. ${ }^{6,7}$ Culture for MTB is more sensitive and specific, but it is expensive and takes on average 2 to 8 weeks' time for the result. ${ }^{20,21}$ Moreover, diagnosis of TB in HIV

Table 4 Diagnostic sensitivity of CBNAAT in sputum smearpositive PTB and sputum smear-negative PTB

\begin{tabular}{|l|l|}
\hline Sputum PTB & Sensitivity of CBNAAT \\
\hline Smear-positive & $100 \%$ \\
\hline Smear-negative & $11.3 \%$ \\
\hline
\end{tabular}

Abbreviations: CBNAAT, cartridge-based nucleic acid amplification test; PTB, pulmonary tuberculosis

Table 5 Sensitivity of CBNAAT in EPTB diagnosis

\begin{tabular}{|c|c|c|c|c|}
\hline & $\begin{array}{l}\text { ZN smear- } \\
\text { positive } \\
\text { EPTB } \\
\text { sample }\end{array}$ & $\begin{array}{l}\text { ZN } \\
\text { smear- } \\
\text { negative } \\
\text { EPTB } \\
\text { sample }\end{array}$ & Total & $p$-Value \\
\hline $\begin{array}{l}\text { CBNAAT-positive } \\
\text { EPTB sample }\end{array}$ & 13 & 3 & 16 & \multirow[t]{2}{*}{$<0.001$} \\
\hline $\begin{array}{l}\text { CBNAAT-negative } \\
\text { EPTB sample }\end{array}$ & 0 & 11 & 11 & \\
\hline Total & 13 & 14 & 27 & \\
\hline
\end{tabular}

Abbreviations: CBNAAT, cartridge-based nucleic acid amplification test; EPTB, extrapulmonary tuberculosis; ZN, Ziehl-Neelsen. patients is even more difficult, as, in HIV-TB coinfection, typical X-ray findings of TB are uncommon. Thus, there is a need for a newer rapid diagnostic test for TB with improved sensitivity and specificity. WHO has recommended CBNAAT as a rapid diagnostic test for TB diagnosis in special cases such as drug-resistant TB, TB in children, TB-HIV coinfection, EPTB, and sputum smear-negative PTB. ${ }^{14}$

In our study, most of the patients (56.2\%) had low CD4 counts of less than 100 cells $/ \mathrm{mm}^{3}$ and had high viral load (93.4\% patients) of more than 1,000 copies/mL. Devi et $\mathrm{al}^{22}$ found that PTB and EPTB were significantly more common in HIV-seropositive patients $(p<0.02)$ in whom the CD4 cell count was low (less than 100 cells $/ \mathrm{mm}^{3}$ ). High viral load and low CD4 count are the markers of advanced HIV disease, which precedes the onset of TB. ${ }^{23}$

The clinical symptoms of the patients at the time of presentation were mainly fever (98.8\%), followed by loss of appetite (93.4\%) and cough (33.8\%), similar to the study conducted by Devi et al $^{22}$ and Kumar et al..$^{23}$

At least 10,000 bacilli per milliliter is a prerequisite for positive sputum microscopy result and is an operator-dependent test. Sensitivity may be low due to lower rates of caseous necrosis and sputum production. ${ }^{4}$ In the present study, only 43 patients were found to be sputum-positive for AFB by direct microscopy and 86 cases were found to be smear-negative, with an overall sensitivity of $30.71 \%$. In cases in which sputum microscopy is done, it can lead to delayed or missed cases, which contributes to increased morbidity and mortality rates and continuing spread of TB in community. Cattamanchi et $\mathrm{al}^{24}$ have reported 43 to $51 \%$ sensitivity of sputum microscopy in HIV, whereas Mecky et al have reported a sensitivity of only $55 \% .{ }^{25}$ Smear-negative cases are treated with broad-spectrum antibiotics course for 7 to 14 days, and if symptoms persisted, TB were suspected. However, by this time, there is delay in starting the specific anti-TB medication and thus it can result in higher mortality. ${ }^{2}$

On the other hand, CBNAAT showed an advantage of significant increase $(p<0.001)$ of $7.8 \%$ in diagnosis of microbiologically confirmed PTB cases over and above the cases diagnosed by sputum smear for AFB, which is consistent with the studies by Alvarez-Uria et al, ${ }^{26}$ Dewan et al, ${ }^{27}$ and Geleta et $\mathrm{al}^{28}$ (increase of $10.8,29$, and $31 \%$, respectively).

Overall, CBNAAT was positive in $38.57 \%$ of PTB cases in this study, but its result varied significantly between $100 \%$ in sputum smear-positive PTB and $11.3 \%$ in sputum smear-negative PTB. Similar results of very high sensitivity of CBNAAT in smear-positive cases but low sensitivity in smear-negative cases were observed in several studies. Dewan et al, ${ }^{27}$ Theron et al, $^{29}$ Geleta et $a l,{ }^{28}$ and Agrawal et $\mathrm{al}^{30}$ found CBNAAT sensitivity of 100, 94.7, 95.2, and 100 in smear-positive PTB 
Table 6 Sensitivity of CBNAAT in EPTB site

\begin{tabular}{|l|l|l|l|l|l|l|}
\hline EPTB specimen & $\begin{array}{l}\text { No. of cases } \\
\text { (total 27) }\end{array}$ & $\begin{array}{l}\text { TB detected } \\
\text { by CBNAAT }\end{array}$ & $\begin{array}{l}\text { TB not } \\
\text { detected by } \\
\text { CBNAAT }\end{array}$ & $\begin{array}{l}\text { TB detected } \\
\text { by ZN } \\
\text { staining }\end{array}$ & $\begin{array}{l}\text { TB not } \\
\text { detected by } \\
\text { ZN staining }\end{array}$ & $\begin{array}{l}\text { Percentage of TB } \\
\text { detected by } \\
\text { CBNAAT (\%) }\end{array}$ \\
\hline Lymph node & 14 & 11 & 3 & 11 & 3 & 78.57 \\
\hline Pleural fluid & 5 & 1 & 4 & 1 & 4 & 20 \\
\hline CSF fluid & 5 & 1 & 4 & 1 & 4 & 20 \\
\hline Ascitic fluid & 2 & 2 & 0 & 0 & 2 & 100 \\
\hline Pericardial fluid & 1 & 1 & 0 & 0 & 1 & 100 \\
\hline
\end{tabular}

Abbreviations: CBNAAT, cartridge-based nucleic acid amplification test; CSF, cerebrospinal fluid; EPTB, extrapulmonary tuberculosis; TB, tuberculosis; ZN, Ziehl-Neelsen.

Table 7 Rifampicin resistance detected by CBNAAT

\begin{tabular}{|l|l|l|}
\hline $\begin{array}{l}\text { Rifampicin } \\
\text { resistance }\end{array}$ & PTB & EPTB \\
\hline Detected & 5 & 0 \\
\hline Not detected & 135 & 27 \\
\hline Total & 140 & 27 \\
\hline
\end{tabular}

Abbreviations: EPTB, extrapulmonary tuberculosis; PTB, pulmonary tuberculosis.

and $32.58,46.8,48.6$, and $79.1 \%$ in smear-negative PTB, respectively ( - Table 8 ).

HIV-TB coinfection can decrease the sensitivity of sputum microscopy (to $47 \%)^{2,32}$; however, it does not significantly affect CBNAAT. Hopewell et $\mathrm{al}^{6}$ suggested that in patients infected with HIV with a CD4 count of less than 200 cells $/ \mathrm{mL}$, there has been better sensitivity of combined smear microscopy and CBNAAT than smear microscopy alone (69.6 vs. 39.1\%; $p=0.05$ ).

Rifampicin resistance was detected in five (3.5\%) cases of PTB; however, no rifampicin resistance was found in EPTB sample. In fact, there were very few EPTB cases. MDR-TB in these five rifampicin-resistant PTB cases were not confirmed as mycobacterial culture (gold standard) was not done in this study. However, according to the study done by Theron et $\mathrm{al}^{29}$ rifampicin resistance is rarely detected alone and MDR-TB was detected in $90 \%$ of rifampicin-resistant patients by CBNAAT.

In our study, maximum cases of EPTB were of LNTB (14 out of 27), followed by pleural fluid TB (5 out of 27). Similar findings were reported by Devi et al, ${ }^{22}$ where the commonest extrapulmonary lesion in the HIV-seropositive patients was found in the lymph nodes $(n=15)$, followed by pleural effusion $(n=11)$. The overall sensitivity of CBNAAT in EPTB was found to be $59.25 \%$ in our study, which is similar to the study done by Scott et $\mathrm{al}^{33}$ (59\%), Shah and Bhabhor ${ }^{34}$ (59\%), Moure et $\mathrm{al}^{35}$ (58.3\%), Armand et $\mathrm{al}^{36}$ (53.1\%), and Pandie et $\mathrm{al}^{37}$ (63.8\%). CBNAAT sensitivity was found to be more than ZN smear AFB microscopy, i.e., 59.25 and $48.1 \%$, respectively. Mittal and $\mathrm{Kumar}^{38}$ compared the diagnostic yield of CBNAAT and ZN staining in serosal fluids from HIV and non-HIV patients with EPTB. Out of 81 EPTB samples ( 21 from HIV and 60 from non-HIV patients), 28 (34.5\%) were both CBNAATand ZN stain-positive, while only 11 (13.58\%) were ZN stain-positive. Out of 21 HIV patients, 4 (19.05\%) were ZN stain-positive and 9 (42.85\%) were CBNAAT-positive. Among 60 non-HIV patients, 7 (11.66\%) were ZN stain-positive and 19 (31.66\%) were CBNAAT-positive, showing that CBNAAT is more sensitive than ZN staining in EPTB in both HIV and non-HIV patients. In our study, CBNAAT testing resulted in a relative increase in detection rate of TB cases by $11 \%$ compared with ZN smear microscopy $(p<0.001)$.

In our study, sensitivity of CBNAAT for diagnosing LNTB was found to be $78.57 \%$, as compared with 72 to $87 \%$ found in Vadwai et $\mathrm{al}^{39}{ }^{39}$ Zeka et $\mathrm{al}^{40}{ }^{40}$ Ligthelm et $\mathrm{al},{ }^{41}$ and Denkinger et al. ${ }^{42}$ However, a negative CBNAAT test does not rule out LNTB. CBNAAT is recommended as an additional test to smear microscopy, culture, and cytology in FNAC (fine needle aspiration cytology) specimens for detection of EPTB in new guideline. ${ }^{43}$

Regarding the diagnosis of TB meningitis, Denkinger et $\mathrm{al}^{42}$ and Tortoli et $\mathrm{al}^{44}$ assessed CBNAAT in CSF samples and found a variable sensitivity of 20 to $86 \%$. CBNAAT detected only one MTB out of the five samples in this study (sensitivity, 20\%), suggesting that a negative CBNAAT result does not rule out TB meningitis. CBNAAT is recommended as an adjunctive test for TB meningitis as per guidelines on ЕРТВ for India. ${ }^{43}$

Table 8 Comparison of the diagnostic yield of sputum microscopy and CBNAAT in PTB in PLHIV

\begin{tabular}{|l|l|l|l|l|}
\hline Study & Sample size & TB-positive & $\begin{array}{l}\text { Sputum microscopy } \\
\text { AFB-positive }\end{array}$ & CBNAAT-positive \\
\hline Present study & $\mathbf{1 6 7}$ & $\mathbf{1 4 0}$ & $\mathbf{4 3}(\mathbf{3 0 . 7 \% )}$ & $\mathbf{5 4}(\mathbf{3 8 \% )}$ \\
\hline Dewan et a $^{27}$ & 100 & $40(40 \%)$ & $11(11 \%)$ & $40(40 \%)$ \\
\hline Bansal et al $^{31}$ & 604 & $91(15.06 \%)$ & & $6(0.99 \%)$ \\
\hline Rao and Sowjanya $^{16}$ & 231 & 59 & $14(6.06 \%)$ & $59(25.54 \%)$ \\
\hline Gupta et al $^{17}$ & 30 & $\mathbf{2 5 ( 8 3 . 3 \% )}$ & $8(26.67 \%)$ & $17(56.7 \%)$ \\
\hline
\end{tabular}

Abbreviations: AFB, acid-fast bacillus; CBNAAT, cartridge-based nucleic acid amplification test; TB, tuberculosis. 
Studies by Rufai et al, ${ }^{45}$ Shah and Bhabhor, ${ }^{34}$ Meldau et $\mathrm{al}^{46}$ and Porcel et $\mathrm{al}^{47}$ have reported much lower sensitivities of CBNAAT in diagnosing pleural fluid TB, i.e., between 15 and $48 \%$. In our study also, the sensitivity of CBNAAT pleural fluid specimens was found to be low, i.e., $20 \%$, with more than half of all pleural TB patients being missed by this test. CBNAAT should not be used exclusively to diagnose pleural TB. ${ }^{43}$ In our study, sensitivity of CBNAAT in diagnosing both ascitic and pericardial fluid were found to be $100 \%$, which is in contrast to studies done by Sharma et al, ${ }^{48}$ Lawn et al, ${ }^{49}$ and Fuladi and Gupta et al, ${ }^{50}$ which showed sensitivity range of 8 to $50 \%$.

\section{Limitation}

We did not compare CBNAAT with mycobacterial culture, the current gold standard for diagnosis of TB. Further studies with large ЕРТВ sample size, comparing the results of CBNAAT with mycobacterial cultures, are needed.

\section{Conclusion}

CBNAAT detects TB in HIV patients in Manipur with greater efficacy than ZN smear microscopy, both in PTB and EPTB. It gives early diagnosis in less than 2 hours. Thus, it decreases delayed or misdiagnosed cases, contributing to early start of treatment and thus decreasing the morbidity and mortality rates. It also detects rifampicin resistance and can be used for screening for MDR-TB.

\section{Conflict of Interest}

None declared.

\section{References}

1 World Health Organization (WHO). Tuberculosis Control: Fourth Global Report.Geneva: World Health Organization; 2010

2 Corbett EL, Watt CJ, Walker N, et al. The growing burden of tuberculosis: global trends and interactions with the HIV epidemic. Arch Intern Med 2003;163(9):1009-1021

3 Getahun H, Gunneberg C, Granich R, Nunn P. HIV infection-associated tuberculosis: the epidemiology and the response. Clin Infect Dis 2010;50(3, Suppl 3) :S201-S207

4 Selwyn PA, Hartel D, Lewis VA, et al. A prospective study of the risk of tuberculosis among intravenous drug users with human immunodeficiency virus infection. $\mathrm{N}$ Engl J Med 1989;320(9):545-550

5 Wallis RS, Pai M, Menzies D, et al. Biomarkers and diagnostics for tuberculosis: progress, needs, and translation into practice. Lancet 2010;375(9729):1920-1937

6 Hopewell PC, Pai M, Maher D, Uplekar M, Raviglione MC. International standards for tuberculosis care. Lancet Infect Dis 2006;6(11):710-725

7 Getahun H, Harrington M, O'Brien R, Nunn P. Diagnosis of smear-negative pulmonary tuberculosis in people with HIV infection or AIDS in resource-constrained settings: informing urgent policy changes. Lancet 2007;369(9578):2042-2049

8 Avashia S, Bansal D, Ahuja K, Agrawal V. Comparison of conventional methods with gene Xpert MTB/RIF assay for rapid detection of mycobacterium tuberculosis and rifampicin resistance in extra-pulmonary samples. Indian J Med Res 2012;4(2):187-188
9 San KE, Muhamad M. Pulmonary tuberculosis in HIV infection: the relationship of the radiographic appearance to CD4 T-lymphocytes count. Malays J Med Sci 2001;8(1):34-40

10 Moore DF, Guzman JA, Mikhail LT. Reduction in turnaround time for laboratory diagnosis of pulmonary tuberculosis by routine use of a nucleic acid amplification test. Diagn Microbiol Infect Dis 2005;52(3):247-254

11 Pai M, Kalantri S, Dheda K. New tools and emerging technologies for the diagnosis of tuberculosis: part II. Active tuberculosis and drug resistance. Expert Rev Mol Diagn 2006;6(3):423-432

12 Helb D, Jones M, Story E, et al. Rapid detection of Mycobacterium tuberculosis and rifampin resistance by use of on-demand, near-patient technology. J Clin Microbiol 2010;48(1):229-237

13 Boehme CC, Nabeta P, Hillemann D, et al. Rapid molecular detection of tuberculosis and rifampin resistance. N Engl J Med 2010;363(11):1005-1015

14 World Health Organization. Automated real-time nucleic acid amplification technology for rapid and simultaneous detection of tuberculosis and rifampicinresistance: Xpert MTB/ RIF assay for the diagnosis of pulmonary and extrapulmonary TB in adults and children: policy update. 2013. Available at: https://apps.who.int/iris/handle/10665/112472. Accessed May 21, 2021

15 Lawn SD, Nicol MP. Xpert ${ }^{\circledR}$ MTB/RIF assay: development, evaluation and implementation of a new rapid molecular diagnostic for tuberculosis and rifampicin resistance. Future Microbiol 2011;6(9):1067-1082

16 Rao DP, Sowjanya KL. Role of CBNAAT in rapid detection of Mycobacterium tuberculosis in PLHIV in a highly prevalent state. J Evid Based Med Healthc 2016;3(38):1896-1898

17 Gupta PP, Mynalli AB, Yadav A. Diagnostic role of cartridge based nucleic acid amplification test in diagnosing tuberculosis in patients co-infected with human immunodeficiency virus. J Med Sci Clin Res 2017;5(5):21841-21848

18 Revised National TB Control Programme. Technical and Operational Guidelines for Tuberculosis Control in India. 2016. Available at: https://tbcindia.gov.in/WriteReadData/ Revised\%20Technical\%20and\%200perational\%20Guidelines/ files/assets/basic-html/page-1.html\#. Accessed May 27, 2021

19 Revised National TB Control Programme Annual Status Report. 2015. Available at: https://tbcindia.gov.in/showfile. php?lid=3166. Accessed May 27, 2021

20 Moore DF, Guzman JA, Mikhail LT. Reduction in turnaround time for laboratory diagnosis of pulmonary tuberculosis by routine use of a nucleic acid amplification test. Diagn Microbiol Infect Dis 2005;52(3):247-254

21 Pai M, Kalantri S, Dheda K. New tools and emerging technologies for the diagnosis of tuberculosis: part II. Active tuberculosis and drug resistance. Expert Rev Mol Diagn 2006;6(3):423-432

22 Devi SB, Naorem S, Singh TJ, Prasad L, Devi TS. HIV and TB co-infection. J Indian Acad Clin Med 2005;6(2):3-9

23 Kumar P, Sharma N, Sharma NC, Patnaik S. Clinical profile of tuberculosis in patients with HIV Infection/AIDS. Indian J Chest Dis Allied Sci 2002;44(3):159-163

24 Cattamanchi A, Dowdy DW, Davis JL, et al. Sensitivity of direct versus concentrated sputum smear microscopy in HIV-infected patients suspected of having pulmonary tuberculosis. BMC Infect Dis 2009;9(2):53-64

25 Mecky M, Tarja L, Wendy W, et al. Sputum microscopy for the diagnosis of HIV-associated pulmonary tuberculosis in Tanzania. Bio Med Cent Pub Health J 2008;8(3):68-73

26 Alvarez-Uria G, Azcona JM, Midde M. Naik PK, Reddy S, Reddy R. Rapid diagnosis of pulmonary and extrapulmonary tuberculosis in HIV-infected patients. Comparison of LED fluorescent microscopy and the GeneXpert MTB/RIF assay in a district hospital in India. Tuberc Res Treat 2012;7(3):4-12

27 Dewan R, Anuradha S, Khanna A, et al. Role of cartridge-based nucleic acid amplification test (CBNAAT) for early 
diagnosis of pulmonary tuberculosis in HIV. J Indian Acad Clin Med 2015;16(2):114-117

28 Geleta DA, Megerssa YC, Gudeta AN, Akalu GT, Debele MT, Tulu KD. Xpert MTB/RIF assay for diagnosis of pulmonary tuberculosis in sputum specimens in remote health care facility. BMC Microbiol 2015;15(10):220-223

29 Theron G, Peter J, van Zyl-Smit R, et al. Evaluation of the Xpert MTB/RIF assay for the diagnosis of pulmonary tuberculosis in a high HIV prevalence setting. Am J Respir Crit Care Med 2011;184(1):132-140

30 Agrawal M, Bajaj A, Bhatia V. Comparative study of gene Xpert with ZN stain and culture in samples of suspected pulmonary tuberculosis. J Clin Diagn Res 2016;10(5):9-12

31 Bansal D, Avashia S, Karothiya M. A study of gene xpert in screening of sputum in HIV positive patients presenting to tertiary care centre. Natl J Community Med 2016;7(8):657-660

32 Carriquiry G, Otero L, Gonzalez LE, et al. A diagnostic accuracy study of XpertMTB/RIF in HIV-positive patients with high clinical suspicion of pulmonary tuberculosis in Lima, Peru. J Clin Diagn Res 2012;7(9):446-456

33 Scott LE, McCarthy K, Gous N, et al. Comparison of Xpert MTB/RIF with other nucleic acid technologies for diagnosing pulmonary tuberculosis in a high HIV prevalence setting: a prospective study. PLoS Med 2011;8(7):e1001061

34 Shah M, Bhabhor U. PCR as diagnostic tool in early detection of extrapulmonary TB. Indian J Med Res 2018;5(2):171-173

35 Moure R, Muñoz L, Torres M, Santin M, Martín R, Alcaide F. Rapid detection of Mycobacterium tuberculosis complex and rifampin resistance in smear-negative clinical samples by use of an integrated real-time PCR method. J Clin Microbiol 2011;49(3):1137-1139

36 Armand S, Vanhuls P, Delcroix G, Courcol R, Lemaître N. Comparison of the Xpert MTB/RIF test with an IS6110-TaqMan real-time PCR assay for direct detection of Mycobacterium tuberculosis in respiratory and nonrespiratory specimens. J Clin Microbiol 2011;49(5):1772-1776

37 Pandie S, Peter JG, Kerbelker ZS, et al. Diagnostic accuracy of quantitative PCR (Xpert MTB/RIF) for tuberculous pericarditis compared to adenosine deaminase and unstimulated interferon- $\gamma$ in a high burden setting: a prospective study. BMC Med 2014;12(3):101-104

38 Mittal M, Kumar R. Comparison of diagnostic yield of GeneXpert MTB/RIF assay and ZN (Ziehl-Neelsen) staining in serosal fluids from HIV and non-HIV patients with extra-pulmonary tuberculosis. Int J Res Med Sci 2017;5(7):2952-2955

39 Vadwai V, Boehme C, Nabeta P, Shetty A, Alland D, Rodrigues C.XpertMTB/RIF: anew pillarindiagnosis of extrapulmonary tuberculosis? J Clin Microbiol 2011;49(7):2540-2545

40 Zeka AN, Tasbakan S, Cavusoglu C. Evaluation of the GeneXpert MTB/RIF assay for rapid diagnosis of tuberculosis and detection of rifampin resistance in pulmonary and extrapulmonary specimens. J Clin Microbiol 2011;49(12):4138-4141

41 Ligthelm LJ, Nicol MP, Hoek KG, et al. Xpert MTB/RIF for rapid diagnosis of tuberculous lymphadenitis from fine-needle-aspiration biopsy specimens. J Clin Microbiol 2011;49(11):3967-3970

42 Denkinger CM, Schumacher SG, Boehme CC, Dendukuri N, Pai M, Steingart KR. Xpert MTB/RIF assay for the diagnosis of extrapulmonary tuberculosis: a systematic review and meta-analysis. Eur Respir J 2014;44(2):435-446

43 INDEX-TB GUIDELINES. Guidelines on extra-pulmonary tuberculosis for India. 2016. Available at: https://www.tbonline.info/media/uploads/documents/index-tb_guidelines_-green_colour_2594164.pdf. Accessed May 27, 2021

44 Tortoli E, Russo C, Piersimoni C, et al. Clinical validation of Xpert MTB/RIF for the diagnosis of extrapulmonary tuberculosis. Eur Respir J 2012;40(2):442-447

45 Rufai SB, Singh S, Singh A, Kumar P, Singh J, Vishal A. Performance of Xpert MTB/RIF on ascitic fluid samples for detection of abdominal tuberculosis. J Lab Physicians 2017;9(1):47-52

46 Meldau R, Peter J, Theron G, et al. Comparison of same day diagnostic tools including Gene Xpert and unstimulated IFN- $\gamma$ for the evaluation of pleural tuberculosis: a prospective cohort study. BMC Pulm Med 2014;14:58

47 Porcel JM, Palma R, Valdés L, Bielsa S, San-José E, Esquerda A. Xpert ${ }^{\circledR}$ MTB/RIF in pleural fluid for the diagnosis of tuberculosis. Int J Tuberc Lung Dis 2013;17(9):1217-1219

48 Sharma SK, Kohli M, Yadav RN, et al. Evaluating the diagnostic accuracy of Xpert MTB/RIF assay in pulmonary tuberculosis. PLoS One 2015;10(10):e0141011

49 Lawn SD, Brooks SV, Kranzer K, et al. Screening for HIV-associated tuberculosis and rifampicin resistance before antiretroviral therapy using the Xpert MTB/RIF assay: a prospective study. PLoS Med 2011;8(7):e1001067

50 Fuladi BA, Gupta P. Challenges in the diagnosis of extrapulmonary tuberculosis: role of Gene Xpert mycobacterium tuberculosis/rifampicin assay. N Engl J Med 2017;5(2):77-84 